\title{
Growth performance, body measurements, carcass composition and some internal organ characteristics in young Pekin ducks
}

\author{
K. Steczny ${ }^{1}$, D. Kokoszynski ${ }^{1 \#}$, Z. Bernacki ${ }^{1}$, R. Wasilewski ${ }^{1}$ \& M. Saleh ${ }^{2}$ \\ ${ }^{1}$ Department of Poultry Breeding, UTP University of Science and Technology, \\ 85-084 Bydgoszcz, Poland \\ ${ }^{2}$ Department of Poultry and Animal Production, Sohag University, Sohag, Egypt
}

(Received 1 March 2016; Accepted 26 April 2017; First published online 3 May 2017)

\begin{abstract}
Copyright resides with the authors in terms of the Creative Commons Attribution 4.0 South African Licence.
See: http://creativecommons.org/licenses/by/4.0/za

Condition of use: The user may copy, distribute, transmit and adapt the work, but must recognise the authors and the South African Journal of Animal Science.
\end{abstract}

\begin{abstract}
The aim of the study was to compare the bodyweight and body measurements, carcass composition, and characteristics of major visceral organs in male and female Pekin ducks. A total of 80 hybrid SM3 Heavy ducks were kept in a conventional building and fed complete commercial diets ad libitum. The male and female were weighed individually at one day old and their bodyweight and body measurements were determined at 21, 35 and 49 days of rearing. On day 49, 20 males and 20 females were chosen for slaughter. After slaughter, the carcasses and visceral organs were collected. No significant differences were observed between males and females in bodyweight ( $1 \mathrm{~d}, 58.6$ vs $56.3 \mathrm{~g}$ to $49 \mathrm{~d}, 3518$ vs $3433 \mathrm{~g}$ ) and feed conversion ratio (FCR) (0-49 d, $2.44 \mathrm{vs} 2.49 \mathrm{~kg} / \mathrm{kg}$ gain). At 35 days old males demonstrated a significantly longer body and shanks and, at 49 days old a significantly longer body than females. The sex of ducks had no significant effect on the percentage of wings, muscles from breast and legs, skin with subcutaneous fat, abdominal fat and carcass remainder. The neck content was significantly greater in male carcasses than female ones. The contents of proventriculus, liver, and spleen in the bodies of males and females were similar. Gizzard percentage was significantly greater in males, and heart percentage was significantly greater in females. Due to their high bodyweight, good FCR, and favourable carcass composition, SM3 Heavy male ducks are more useful as broiler duck than females.
\end{abstract}

Keywords: carcasses, digestive system, growth, Pekin duck, sex

\#Corresponding author: kokoszynski@gmail.com

\section{Introduction}

Because of their rapid growth rate, Pekin ducks are ideally suited to meat production. The birds are raised mainly for tasty meat; hence the main goal of breeding ducks is on improving meatiness (Kokoszynski \& Bernacki, 2011; Xie et al., 2014). Commercial SM3 Heavy ducks are hybrids that were born to parents that were imported from Great Britain and were approved for distribution in Poland in 2013 (Wencek et al., 2014). Carcasses from the SM3 Heavy hybrid live up to consumer expectations of duck meat, owing to their good muscling, in particular the large amount of breast muscle and relatively low content of skin with subcutaneous and abdominal fat (Kokoszynski et al., 2016). Pekin duck bodyweight and slaughter value were investigated by Kokoszynski \& Korytkowska (2003), Bernacki et al. (2006; 2008), Biesiada-Drzazga et al. (2012), Sari et al. (2013) and Oh et al. (2015). Sari et al. (2013) reported that male and female Pekin ducks had the highest daily weight gains between 28 and 42 days old, though males are significantly heavier than females from six weeks of growth. Kokoszynski \& Korytkowska (2003) observed the highest weight gains in Pekin males and females between 35 and 49 days of rearing. In a study by Adamski \& Bernacki (2002), the bodyweight and measurements, chest circumference and shank length in male and female Pekin ducks increased most between 21 and 35 days, trunk length between 21 and 28 days, and sternum length between 28 and 35 days old. The growth and development of muscle, adipose and bone tissue could be evaluated based on the dissection results. In a study by Kokoszynski et al. (2016), the carcasses of 49-dayold Pekin broiler ducks of both sexes contained more breast muscle (16.9-17.7\%) than leg muscle (12.7$13.6 \%$ ). The development of ducks is also reflected in the weight and dimensions of their visceral organs. The structure and metric traits of the digestive system and other visceral organs of ducks, depending on genotype, age, sex, diet and season of the year, were investigated, among others, by Farhad (2009), Downing (2010), and Wasilewski et al. (2015). Because the growth and development traits of SM3 Heavy 
hybrid ducks had never been studied in Poland, this motivated the authors to conduct this research. Since a small number of studies had determined the effect of sex on meat traits and the development of visceral organs in ducks, the present study aimed to compare bodyweight and measurements in young Pekin males and females, and to determine dressing percentage, carcass composition and major visceral organs development.

\section{Materials and Methods}

A total of 80 one-day-old sexed SM3 Heavy Pekin ducks (1: 1 sex ratio) were used in the study. Throughout the study, the birds were kept in a conventional building in four pens with an area of $12 \mathrm{~m}^{2}$, each with 10 males and 10 females and were reared for 49 days. The birds were fed complete commercial waterfowl diets ad libitum. Table 1 shows data on the ingredient and chemical compositions of the commercial diets fed to the ducks during the rearing period. Fresh drinking water was available throughout the study.

Table 1 Composition of the diets for male and female ducks

\begin{tabular}{|c|c|c|}
\hline Ingredient ( $\mathrm{g} / \mathrm{kg}$ as fed) & $\begin{array}{l}\text { Starter } \\
1-21 d\end{array}$ & $\begin{array}{c}\text { Grower/finisher } \\
22-49 \text { d }\end{array}$ \\
\hline Maize & 334.2 & 437.9 \\
\hline Ground wheat & 250.0 & 250.0 \\
\hline Wheat meal & 20.0 & 25.0 \\
\hline Soya bean meal (465 g CP/kg) & 275.0 & 173.0 \\
\hline Sunflower meal (390 g CP/kg) & 15.0 & 20.0 \\
\hline Rape seed meal (347 g CP/kg) & 10.0 & 10.0 \\
\hline Corn DDGS (280 g CP/kg) & 30.0 & 30.0 \\
\hline Soya oil & 33.0 & 26.0 \\
\hline Limestone & 12.9 & 9.9 \\
\hline Monocalcium phosphate & 10.6 & 7.4 \\
\hline Sodium chloride & 2.7 & 2.4 \\
\hline Sodium bicarbonate & 1.0 & 1.4 \\
\hline DL-methionine & 0.5 & 1.0 \\
\hline L-lysine & 0.1 & 1.0 \\
\hline Vitamin-mineral premix ${ }^{\mathrm{A}}$ & 5.0 & 5.0 \\
\hline \multicolumn{3}{|c|}{ Chemical composition of diets ( $\mathrm{g} / \mathrm{kg}$ as fed) } \\
\hline DM & 908.2 & 892.8 \\
\hline $\mathrm{CP}$ & 206.5 & 176.9 \\
\hline Crude fat & 57.4 & 49.6 \\
\hline Crude fibre & 44.5 & 35.3 \\
\hline Crude ash & 49.1 & 41.7 \\
\hline $\mathrm{N}$-free extracts & 550.7 & 589.3 \\
\hline ME (MJ) & 12.9 & 12.2 \\
\hline
\end{tabular}

\footnotetext{
${ }^{A} 1 \mathrm{~kg}$ of vitamin-mineral premix provided; retinol $10000 \mathrm{IU}$, cholecalciferol $2500 \mathrm{IU}, \alpha$-tocopherol $20.00 \mathrm{mg}$, thiamine 0.5 $\mathrm{mg}$, riboflavin $5.00 \mathrm{mg}$, niacinamide $20.00 \mathrm{mg}$, pyridoxine $1.0 \mathrm{mg}$, cobalamin $0.02 \mathrm{mg}$, folic acid $0.5 \mathrm{mg}$, menadione 2.5 $\mathrm{mg}$, choline chloride $200.00 \mathrm{mg}$, Fe $45.00 \mathrm{mg}$, Mn $62.5 \mathrm{mg}, \mathrm{Zn} 50.00 \mathrm{mg}$, Cu $5.00 \mathrm{mg}$, Se $0.25 \mathrm{mg}$, I $1.3 \mathrm{mg}$.

DDGS: distiller's dried grains with solubles, DM: dry matter, CP: crude protein
} 
From 1 to 21 days old, the males and females received a complete commercial diet containing $20.65 \%$ crude protein (CP) and $12.9 \mathrm{MJ}$ metabolizable energy (ME) per kg feed. From 22 to 49 days they were fed a complete diet containing 17.69\% CP and 12.2 MJ ME. The chemical composition of the diets was determined in the Department of Animal Nutrition laboratory at UTP University of Science and Technology in Bydgoszcz, Poland. The CP and energy content of the diets conformed with the Nutrient Requirements for Animals (Rutkowski, 2005). The study was approved by the Ethical Committee (Approval no 27 of 2012) in Bydgoszcz, Poland.

One-day-old ducklings were weighed individually with Precisa 5/12 electronic scales (Medicat, Zurich, Switzerland) to the nearest $0.1 \mathrm{~g}$, after which they were weighed at 21,35 and 49 days old using electronic crane scales (Jotafan, Krakow, Poland) to the nearest $1 \mathrm{gram}$. The body measurements of birds were determined at 21,35 , and 49 days old.

The birds were tape-measured with an accuracy of $1 \mathrm{~mm}$ for body length (between the first cervical vertebra and posterior superior tuberosity of the ischium), length of trunk (between shoulder joint and posterior superior tuberosity of the ischium), length of shank (between tarsal joint and posterior area of the fourth toe at its base), length of keel (from the anterior to the posterior edge of the keel), and chest circumference (behind wings through anterior edge of the keel and middle thoracic vertebra).

At 49 days of rearing, 20 males and 20 females (five males and five females from each pen, that is, 40 birds in total with bodyweight close to the mean weight of each sex) were selected and subjected to slaughter, defeathering and evisceration. The intestines were removed during the evisceration process. The lengths of the small intestine, caeca, and colon were tape-measured with an accuracy of $1 \mathrm{~mm}$. The total length of the intestine and its parts was converted to $100 \mathrm{~g}$ of the pre-slaughter weight. In addition, the gizzard (without digesta), proventriculus (without digesta), liver (without gallbladder), heart, and spleen were removed and weighed, and their percentage in pre-slaughter weight was calculated. The carcasses were dissected into breast muscles, leg muscles, neck without skin, wings with skin, skin with subcutaneous fat, and abdominal fat. The remainder of the carcass was collected after dissection. It contained the skeleton and some skeletal muscles.

The numerical data were analysed statistically with the Statistica program (2002). The arithmetic mean and standard error (SE) were calculated for various traits, and significant differences between means were verified with one-way analysis of variance. The following linear model was used:

$$
y_{i j}=\mu+a_{i}+e_{i j}
$$

where: $y_{i j}$ is the value of the analysed trait

$\mu$ is the overall mean of the analysed trait

$a_{i}$ is the effect of $i^{\text {th }}$ sex

$e_{i j}$ is the random error

\section{Results}

The average bodyweights and standard error were $58.6 \pm 0.1 \mathrm{~g}$ for males and $56.3 \pm 0.1 \mathrm{~g}$ for females and the weight increased with age (Table 2). The body measurements of the male and female hybrids

Table 2 Mean and standard error (SE) bodyweight and measurements in Pekin ducks

\begin{tabular}{lcccccc}
\hline \multirow{2}{*}{ Trait } & \multicolumn{5}{c}{ Age (days) - sex } \\
\cline { 2 - 7 } & \multicolumn{2}{c}{$\mathbf{2 1}$} & \multicolumn{2}{c}{$\mathbf{3 5}$} & \multicolumn{2}{c}{$\mathbf{4 9}$} \\
\cline { 2 - 7 } & Male & Female & Male & Female & Male & Female \\
\hline Bodyweight (g) & $830 \pm 9.5$ & $793 \pm 7.8$ & $225 \pm 11.1$ & $2216 \pm 10.7$ & $3533 \pm 9.4$ & $3432 \pm 11.4$ \\
Body length (cm) & $27.9 \pm 0.1$ & $27.6 \pm 0.1$ & $42.2^{\mathrm{a}} \pm 0.1$ & $40.3^{\mathrm{b}} \pm 0.1$ & $46.3^{\mathrm{a}} \pm 0.1$ & $43.9^{\mathrm{b}} \pm 0.1$ \\
Trunk length (cm) & $17.6 \pm 0.1$ & $16.9 \pm 0.1$ & $27.5 \pm 0.1$ & $27.0 \pm 0.1$ & $27.6 \pm 0.1$ & $27.2 \pm 0.1$ \\
Chest circumference (cm) & $19.9 \pm 0.1$ & $19.5 \pm 0,1$ & $30.5 \pm 0.1$ & $30.2 \pm 0.1$ & $37.0 \pm 0.1$ & $36.5 \pm 0.1$ \\
Keel length (cm) & $5.4 \pm 0.1$ & $5.3 \pm 0.1$ & $10.2 \pm 0.1$ & $10.0 \pm 0.1$ & $13.6 \pm 0.1$ & $13.2 \pm 0.1$ \\
Shank length (cm) & $6.9 \pm 0.2$ & $2.1 \pm 0.1$ & $9.2^{\mathrm{a}} \pm 0.1$ & $8.6^{\mathrm{b}} \pm 0.1$ & $9.3 \pm 0.1$ & $8.8 \pm 0.1$
\end{tabular}

\footnotetext{
${ }^{a . b}$ Row means with different superscripts differ significantly at $P<0.05$
} 
increased up to 49 days old, which suggests that the males and females did not stop growing. Compared with females, males demonstrated significantly longer bodies (the trunk with the neck) and shanks at 35 days old, and again at 49 days. In terms of trunk length, keel length and chest circumference, non-significant differences were observed between males and females (Table 2).

The daily weight gains were higher in males than in females (Table 3). The highest daily weight gains in males and females were noted between 22 and 35 days old, and the lowest until 21 days of growth. Compared with females, males consumed less feed to 21 days old. However, they showed a poorer feed conversion ratio (FCR) per $\mathrm{kg}$ of the weight gain over that period. Between 22 and 35 and between 36 and 49 days old and throughout the rearing period (1-49 days old) males consumed more feed than females. Males demonstrated poorer FCR than females between 22 and 35 days old and better FCR between 36 and 49 days and throughout the rearing period (Table 3 ).

Table 3 Mean and standard error (SE) bodyweight gains and feed consumption and feed conversion ratio in Pekin ducks

\begin{tabular}{lcccc}
\hline \multirow{2}{*}{ Trait } & \multicolumn{4}{c}{ Age (days) } \\
\cline { 2 - 5 } & $\mathbf{1 - 2 1}$ & $\mathbf{2 2 - 3 5}$ & $\mathbf{3 6 - 4 9}$ & $\mathbf{1 - 4 9}$ \\
\hline Bodyweight gain in males (g/day) & $36.7 \pm 0.1$ & $102.1 \pm 0.1$ & $91.0 \pm 2.9$ & $70.9 \pm 2.9$ \\
Bodyweight gain in females (g/day) & $35.1 \pm 0.7$ & $101.6 \pm 1.3$ & $86.9 \pm 3.8$ & $68.9 \pm 3.8$ \\
Feed intake per male (kg) & 2.07 & 2.82 & 3.57 & 8.46 \\
Feed intake per female (kg) & 2.09 & 2.79 & 3.53 & 8.41 \\
Feed conversion ratio in males (kg/kg) & 2.68 & 1.98 & 2.80 & 2.44 \\
Feed conversion ratio in females (kg/kg) & 2.84 & 1.96 & 2.90 & 2.49 \\
\hline
\end{tabular}

According to Table 4, the average body weight of 49-day-old males selected for dissection was higher than that of females $(P>0.05)$. Dressing percentage in the males and females was high and exceeded $70 \%$. Females showed a higher dressing percentage $(P>0.05)$ than males. The carcasses from 49-day-old males contained significantly $(P<0.05)$ more neck compared with female carcasses. The percentages of wings, breast muscles, and leg muscles were non-significantly $(P>0.05)$ higher in male carcasses than female ones. A reverse relationship was established for the proportion (\%) of abdominal fat, skin with subcutaneous fat, and the carcass remainder (Table 4).

Table 4 Mean and standard error (SE) bodyweight, dressing percentage and proportion of components in carcass from 49-day-old Pekin ducks

\begin{tabular}{lcc}
\hline Trait & Male & Female \\
\hline Body weight before slaughter (g) & $3518 \pm 19.3$ & $3433 \pm 18.3$ \\
Carcass weight (g) & $2465 \pm 15.7$ & $2418 \pm 11.4$ \\
Dressing percentage (\%) & $70.1 \pm 0.2$ & $70.4 \pm 0.2$ \\
Neck (\%) & $7.3^{\mathrm{a}} \pm 0.1$ & $6.6^{\mathrm{b}} \pm 0.1$ \\
Wings (\%) & $12.6 \pm 0.2$ & $12.2 \pm 0.3$ \\
Breast muscles (\%) & $18.0 \pm 0.4$ & $17.6 \pm 0.4$ \\
Leg muscles (\%) & $13.5 \pm 0.4$ & $13.2 \pm 0.3$ \\
Skin with subcutaneous fat (\%) & $24.1 \pm 0.5$ & $24.9 \pm 0.7$ \\
Abdominal fat (\%) & $0.5 \pm 2.4$ & $0.7 \pm 2.1$ \\
Remainders of carcass (\%) & $24.0 \pm 0.5$ & $24.8 \pm 0.2$ \\
\hline a.b Row means with different superscripts differ significantly at $P<0.05$ &
\end{tabular}


In terms of the length of the intestine and the digestive organs, no significant differences were found between male and female SM3 Heavy ducks (Table 5). The relative total lengths of the intestine, small intestine and caeca were greater in females than in males. However, males were characterized by a greater relative length of colon than females. The percentage of proventriculus and liver in the body of 49 -day-old males was similar to that in females, with no significant differences. The gizzard percentage was significantly higher in males than in females, while the opposite was true for the heart percentage. The spleen percentage in the body of 49-day-old birds was the same in males and females (Table 5).

Table 5 Mean and standard error (SE) relative intestinal length and proportion of some visceral organs in live weight in 49-day-old Pekin ducks

\begin{tabular}{lcc}
\hline \multicolumn{1}{c}{ Trait } & Male & Female \\
\hline Small & Intestine (cm/100 $\mathbf{~ g ~ B W ) ~}$ & \\
Caeca & $6.31 \pm 0.11$ & $6.34 \pm 0.10$ \\
Colon & $1.15 \pm 0.01$ & $1.16 \pm 0.01$ \\
Total intestine & $0.35 \pm 0.01$ & $0.34 \pm 0.01$ \\
& $7.81 \pm 0.11$ & $7.84 \pm 0.12$ \\
Gizzard & Proportion in bodyweight (\%) \\
Proventriculus & $3.04^{\mathrm{a}} \pm 0.07$ & $2.77^{\mathrm{b}} \pm 0.06$ \\
Liver & $0.25 \pm 0.01$ & $0.24 \pm 0.01$ \\
Heart & $1.56 \pm 0.04$ & $1.67 \pm 0.09$ \\
Spleen & $0.44^{\mathrm{a}} \pm 0.01$ & $0.49^{\mathrm{b}} \pm 0.01$ \\
\end{tabular}

${ }^{a . b}$ Row means with different superscripts differ significantly at $P<0.05$

BW: bodyweight

\section{Discussion}

As in the current experiment, Sari et al. (2013) and Damaziak et al. (2014) found the bodyweight of Pekin ducks increased with age. The average bodyweight of both males and females determined at 49 days old was high. The bodyweight of the ducks examined at 49 days old was consistent with the recorded performance results of SM3 Heavy hybrids in Poland (Wencek et al., 2016). Lower bodyweights in 49-dayold male and female Pekin ducks were reported by Mazurowski et al. (2015). In a study by Wasilewski et al. (2015), 49-day-old SM3 Heavy males and females weighed 2952.2 and $2857.2 \mathrm{~g}$, respectively. Similarly, as in the studies by Biesiada-Drzazga et al. (2012) and Sari et al. (2013), males were heavier than females throughout the rearing period. Unlike the current study, these two experiments reported a significant effect of the sex on the bodyweight of ducks from six weeks old. The increased difference in body weight between male and female ducks from 35 to 49 days old may be indicative of more intensive growth of the males than females at a later age. Hong et al. (2014) reported that the higher bodyweight gains in Pekin males than females after four weeks old, with similar feed consumption, could be because of the effect of androgenic hormones on protein metabolism and growth rate of skeletal muscles in males. The highest daily weight gains of the male and female SM3 Heavy ducks in the current experiment were noted between 22 and 35 days old, which is consistent with the results of earlier studies on Pekin ducks of both sexes (Kokoszynski \& Korytkowska, 2003; Bernacki et al., 2006; Kowalczyk et al., 2012). In a study by Biesiada-Drzazga et al. (2011), the mean daily weight gains of Star $53 \mathrm{HY}$ (Pekin) ducks from 1 to 49 days old were $61.3 \mathrm{~g}$ for males and $48.9 \mathrm{~g}$ for females, of which the difference in BW was lower compared with the male and female Pekin ducks evaluated in the current study in the same period. Lower daily weight gains in Pekin ducks of both sexes between 1 and 49 days old were also reported by Kokoszynski and Korytkowska (2003) and Bernacki et al. (2006), who maintained ducks under similar environmental and feeding conditions.

At 49 days old, the ducks showed a shorter body but longer shanks and greater chest circumference, compared with hybrid ducks of similar body weight in an experiment by Kokoszynski (2011). This may suggest that the conformation of Pekin ducks varies according to their origin and the direction of breeding in pedigree flocks. The birds demonstrated poorer FCR (feed conversion ratio), compared with broiler ducks 
investigated by Erdem et al. (2015), and better than in an experiment reported by Bernacki et al. (2008) with Pekin-type hybrid ducks. Feed conversion per $\mathrm{kg}$ meat (total breast and leg muscles) obtained from 49-dayold SM3 Heavy ducks (after conversion) was $10.89 \mathrm{~kg}$ in males and $11.29 \mathrm{~kg}$ in females, which is much lower than reported by Kowalczyk et al. (2012), where Pekin ducks of both sexes (line A55) needed as much as $19.11 \mathrm{~kg}$ of feed per $\mathrm{kg}$ meat at the same age. Kokoszynski (2011) reported that feed conversion per $\mathrm{kg}$ meat (total breast and leg muscles) in 49-day-old Star 53 HY hybrid ducks averaged $11.19 \mathrm{~kg}$ in males and $11.10 \mathrm{~kg}$ in females. The same study observed much poorer feed conversion per $\mathrm{kg}$ meat in Pekin duck hybrids obtained from genetic reserve parents. In seven-week-old ducks from the same study, the mean feed conversion per $\mathrm{kg}$ meat was $16.88 \mathrm{~kg}$ in males and $19.09 \mathrm{~kg}$ in females.

The percentage of eviscerated carcass with neck in the pre-slaughter weight of the ducks (dressing percentage) was higher in 49 -day-old Star $53 \mathrm{HY}$ ducks $(69.3 \%$ in males, $65.3 \%$ in females) evaluated by Biesiada-Drzazga et al. (2011). Kokoszynski (2011) reported the dressing percentage of 49-day-old ducks as $69.8 \%$ in males and $72.7 \%$ in females. In turn, Witak (2008) found much lower dressing percentages in male $(61.7 \%)$ and female (60.9) Pekin ducks aged 49 days, compared with the birds studied in the current experiment. Murawska et al. (2008) observed a higher dressing percentage in heavier ducks, which is associated mainly with a lower percentage of offal components (head, feet, inedible viscera) and giblets.

Muscle tissue is the most valuable component in the carcass of all animals. The weight of muscles in the poultry carcass is essentially determined by the weight of breast muscle and leg muscle, as reported by Kokoszynski \& Korytkowska (2003), Gorska et al. (2014) and Kokoszynski et al. (2015). In this study the breast muscle accounted for 15.0 to $18.0 \%$ of the weight of carcass with the neck, which is less than reported by Kokoszynski (2011), where the proportion of breast muscle in 49-day-old Pekin ducks was $19.6 \%$ in males and $19.4 \%$ in females. This may indicate that the ducks were subjected to different selection pressures in terms of the percentage of breast muscles, which are the most valuable part of the carcass.

As reported by Biesiada-Drzazga et al. (2011), leg muscles accounted for 9.9 (in females) to $12.1 \%$ (in males) of eviscerated carcass in 49-day-old Pekin ducks, which is less than in the birds studied in the current experiment (13.5\% in males and $13.2 \%$ in females). In an experiment by Biesiada-Drzazga et al. (2011) and Kokoszynski et al. (2016), similarly to the current study, male carcasses had higher leg muscle content compared with female carcasses. In terms of the percentage of wings in the carcass, the males and females were similar to those investigated by Kowalczyk et al. (2012). Ducks, especially the Pekin type, are characterized by high body fat. The content of skin with subcutaneous fat in the carcasses of male and female Pekin ducks ranges from 23.7 to $28.1 \%$ on average and may exceed $30 \%$ (Kokoszynski \& Bernacki, 2011; Kowalczyk et al. 2012; Kokoszynski et al., 2015). In the current study, the proportion of skin with subcutaneous fat was at an intermediate level, i.e. 24.1 and $24.9 \%$ in males and females, respectively.

The digestive system grows at different rates in different poultry species. In seven-day-old ducks, the small intestine is 1.6 times longer than in turkey poults, which weigh almost half as much at the same age (Konarkowski, 2006). According to Wu et al. (2012), the relative development of the intestine is greatest during the first week of age and decreases as birds age. In Pekin ducks the morphological and functional development of the digestive tract is terminated after 7 weeks old (Watkins et al. 2004). In the current study, the ducks of both sexes did not differ significantly in the percentages of the length of different intestinal parts, which contradicts Downing (2010) who showed that the sex of birds has an effect on relative intestinal length $(\mathrm{cm} / 100 \mathrm{~g}$ live weight). The proportion of different intestinal parts in the SM3 Heavy males and females evaluated in the current study is similar to that in male and female Pekin hybrid ducks investigated by Wasilewski et al. (2015). This was likely associated with good uniformity of the examined ducks in terms of body weight.

Like in the study by Wasilewski et al. (2015), the male ducks showed a greater proportion of gizzard than the females. As reported by Kokoszynski et al. (2017), the high proportion of gizzard in the body of birds may be indicative of good muscle growth, which has a positive impact on the particle size of digesta and nutrient absorption. The results of the current experiment support this statement. Heavier males with a greater proportion of gizzard in the body were characterized by better feed conversion (as reflected in lower FCR) compared to females. The proportion of proventriculus, liver and spleen was similar in both sexes. Meanwhile, Downing (2010) observed that the proportion of liver in the body was higher in males than in females, which disagrees with the current findings. Murawska et al. (2012) reported a significant effect of the age (and consequently the body weight) on the heart percentage in the body of ducks. The proportion of the heart in the body was $1 \%$ in 1 -week-old ducks of both sexes and only $0.65 \%$ in birds aged 8 weeks. Bartyzel et al. (2005) reported on the heart percentage being lower in domestic than wild birds.

\section{Conclusions}

During the seven-week rearing period, males had greater body weight, body measurements, and the daily weight gains, compared with females. The sex of birds had a significant effect on the body length (35 
and 49 days) and the length of shanks (35 days old). Male carcasses demonstrated a better muscling (a higher content of breast and leg muscles) and lower fatness (content of skin with subcutaneous fat and abdominal fat), compared with females. In the body of 49-days-old males, the proportion of gizzard was significantly higher, and that of heart - lower than in females. The relative length of the intestine and its parts (per $100 \mathrm{~g}$ of BW) was similar in males and females.

\section{Acknowledgments}

This study was realized from statutory research funds BS-1/2012 assigned by the Polish Ministry of Science and Higher Education.

\section{Authors' Contributions}

KS wrote the manuscript. DK, the doctoral student's tutor, checked the manuscript and made the corrections. DK, ZB and RW developed the methodology and performed the tests on a farm. RW and MS measured the digestive system. DK made the calculations. Finally, all the authors commented on the early and final responses of the manuscript.

\section{Conflict of Interest Declaration}

None of the authors of this work has a financial or other relationship with people or organizations that could influence inappropriately or bias the contents of this paper.

\section{References}

Adamski, M. \& Bernacki, Z., 2002. Evaluation of growth and correlation between meat of ducks of pedigree strain A55. Rocz. Nauk. Zoot. Supl. 16, 87-93.

Bartyzel, B., Karbowicz, M. \& Bartyzel, I., 2005. A comparison of body and heart size between the mallard and Pekin duck. Veterinaria Ir Zootechnica 29, 22-25.

Bernacki, Z., Kokoszynski, D. \& Mallek, T., 2008. Evaluation of selected meat traits in seven-week old duck broilers. Anim. Sci. Pap. Rep. 26, 165-174.

Bernacki, Z., Adamski, M., Kuzniacka, J. \& Kokoszynski, D., 2006. Comparison of meat traits in ducks of different origin to nine weeks of age. Rocz. Nauk. Zoot. 33, 41-57.

Biesiada-Drzazga, B., Charuta, A., Janocha, A. \& Leczycka, J., 2011. Assessment of slaughter value Pekin ducks STAR 53 HY. Rocz. Nauk. PTZ. 7, 109-116.

Biesiada-Drzazga, B., Gruzewska, A., Charuta, A., Litwa, M. \& Nasilowska, A., 2012. Study on growth body conformation and slaughter value of STAR 53 HY ducks. Rocz. Nauk. Zoot. 39, 225-235.

Damaziak, K., Michalczuk, M., Adamek, D., Czaplinski, M., Niemiec, J., Goryl A. \& Pietrzak, D., 2014. Influence of housing system on the growth and histological structure of duck muscles. S. Afr. J. Anim. Sci. 44, 97-109.

Downing, J. A., 2010. Commercial duck production for bird welfare, environmental benefits and efficiency. RIRDC, Barton, Australia, p209.

Erdem, E., Onbasilar E.E. \& Gucuyener Hacan O., 2015. Effects of 16L : 8 D photoperiod on growth performance, carcass characteristics, meat composition, and blood parameters of Pekin ducks. Turk. J. Vet. Anim. Sci. 39, 568575.

Farhad, A., 2009. Carcass characteristics of Pekin ducks selected for grater breast muscle thickness using ultrasound scanning in response to dietary protein. Res. J. Agric \& Biol. Sci. 5, 731-739.

Gorska, A., Gorski J. \& Mroz, E., 2014. Effect of inter-strain crossbreeding in diallele design (4x4) on growth, weight of carcass and weight of basic groups of muscles in Pekin duck crossbreds. Europ. Poult. Sci. 78, 1-16.

Hong, E.C., Heo, K.N., Kim, H.K., Kang, B.S., Kim, C.D., Choo, H.J., Choi, H.C., Mushtag, M.M.H., Purnin, R. \& Kim. J.H., 2014. Growth performance, carcass yield and meat quality of Korean native duck. J. Agric. Sci. Tech. A4, 76-85.

Kokoszynski, D., 2011. Evaluation of meat traits in commercial crossbreds of Pekin type ducks. UTP University of Science and Technology, Bydgoszcz, dissertation 147, 113 p.

Kokoszynski, D. \& Bernacki, Z., 2011. Comparison of meat performance of Pekin ducks from two conservative flocks. J. Cent. Eur. Agric. 12, 215-225.

Kokoszynski, D. \& Korytkowska H., 2003. The evaluation of growth and post-slaughter traits of ducks from two pedigree strains. Zesz. Nauk. Prz. Hod. 68, 79-84.

Kokoszynski, D., Bernacki, Z., Saleh. M., Steczny, K. \& Binkowska, M., 2017. Body conformation and internal organs characteristics of different commercial broiler lines. Braz. J. Poult Sci. 19, 47-52.

Kokoszynski, D., Kotowicz, M., Brudnicki, A., Bernacki, Z., Wasilewski PD. \& Wasilewski R., 2016. Carcass composition and quality of meat Pekin ducks finished on diets with varying levels of whole wheat grain. Anim. Prod. Sci. http;//dx.org/10.1071/AN15810.

Kokoszynski, D., Wasilewski, R., Steczny, K., Bernacki, Z., Kaczmarek, K., Saleh, M., Wasilewski, PD. \& Biegniewska, M., 2015. Comparison of growth performance and meat traits in Pekin ducks from different genotypes. Europ. Poult. Sci. 79, 1-11.

Konarkowski, A., 2006. Development of small intestine in chicks. Polish Poultry 7, 21-23.

Kowalczyk, A, Lukaszewicz, E., Adamski, M. \& Kuzniacka, J., 2012. Carcass composition and meat characteristics of Pekin ducks in relation to age at slaughter and level of maize distiller's dried grains with solubles in diets. J. Anim. Feed Sci. 21, 157-167. 
Mazurowski, A., A. Frieske, D. Kokoszynski, S. Mroczkowski, Z. Bernacki \& Wilkanowska, A., 2015. Examination on growth hormone gene polymorphism and its association with body weight and selected body dimensions in ducks. Folia Biol. 63, 43-50.

Murawska, D., 2012. The effect of age on the growth rate of tissues and organs and the percentage content of edible and nonedible carcass components in Pekin ducks, Poult. Sci. 91, 2030-2038.

Oh, S.T., Zheng, L., Kwon, H.J., Choo, Y.K., Lee, K.W., Kang, C.W. \& B.K. An., 2015. Effects of dietary fermented Chlorella vulgaris $(C B T \AA)$ on growth performance, relative organ weights, cecal microflora, tibia bone characteristics, and meat qualities in Pekin ducks. Asian Australas. J. Anim. Sci. 28, 95-101.

Rutkowski, A., 2005. Nutrient requirements of ducks. In: Nutrient standards of poultry. Dietary recommendations and nutritional value of feeds. Ed: Smulikowska, S., Rutkowski, A., Kielanowski Institute of Animal Physiology and Nutrient PAS, Jablonna. pp. 71-76.

Sari, M, Tilki, M., Onk, K. \& Isik, S., 2013. Effects of production system and gender on live weight and body measurements in Pekin ducks. Ataturk Universitesi Vet. Bil. Derg. 8, 112-121.

Statistica PL, 2002. ver. 6, series 1101.

Wasilewski, R., Kokoszynski, D., Mieczkowska A. \& Bernacki Z., 2015. Structure of the digestive system of ducks depending on sex and genetic background. Acta Vet. Brno 84, 125-131.

Watkins, E., Butler, P. \& Kenyon B., 2004. Posthatch growth of the digestive system in wild and domesticated ducks. Br. Poult. Sci. 45, 331-341.

Wencek, E., Kaluzna, I., Kozlecka, M., Miszkiel, I., Palyszka M., Prokopiak, H., Radziszewska, J., Suchocki, W., Winiarski, K. \& Adamski, M., 2014. Results of poultry performance recording in 2013. Poultry News. Ed. National Poultry Council, Chamber of Commerce, Warsaw, Poland. pp.211.

Wencek, E., Kaluzna, I., Kozlecka, M., Miszkiel, I., Palyszka M., Prokopiak, H., Radziszewska, J., Suchocki, W., Winiarski, K. \& Adamski, M., 2016. Results of poultry performance recording in 2015. Poultry News. Ed. National Poultry Council, Chamber of Commerce, Warsaw, Poland. pp.217.

Witak, B., 2008. Tissue composition of carcass, meat quality and fatty acid content of ducks of commercial breeding line at different ages. Arch. Tierz. 51, 266-275.

Wu, L., Guo, X. \& Fang, Y., 2012. Effect of diet dilution ratio at early age on growth performance, carcass characteristics, and hepatic lipogenesis of Pekin ducks. Braz. J. Poult. Sci. 14, 43-49.

Xie, M., Jiang, Y., Tang. J., Wen, ZG., Huang, W. \& Hou, SS., 2014. Effects of stocking density on growth performance, carcass traits, and foot pad lesions of white Pekin ducks. Poult. Sci. 93, 1644-1648. 